
as France snares fusion project

\section{PARIS}

France has been chosen to host abillion-dollar international thermonuclear experiment. After an 18-month stalemate over whether Japan or France should host the project ITER, the Japanese finally bowed out on 28 June - in return for a hefty compensation package.

Scientists hope that, now the experiment's location has been decided, it could be up and running by 2015 (see 'Securing the funds'). If all goes well, it will be the first fusion experiment that generates more energy than it uses.

The promise of fusion is well known. Using the same reactions that power the stars, hydrogen nuclei can be fused to produce helium, releasing huge amounts of energy - and no high-level radioactive waste. But the line that usable fusion power is 40 years away, and always will be, is sadly just as familiar.

Recent progress has been promising, however, especially for tokamak reactors, in which hot plasma is confined in a floating doughnut shape by superconducting magnets. Both Europe's JET and Japan's JT-60 tokamaks have achieved short periods in which the energy released approaches the energy put in: JET holds the record, with a maximum power output of 16 megawatts. At more than 12 metres across, the plasma ring in ITER will be about twice as big as JET's, and will hopefully generate 400-700 megawatts of power.

Negotiations over ITER's home have been deadlocked since December 2003. The United States and South Korea backed a Japanese site at Rokkasho, while China and Russia supported the European Union's bid for Cadarache in southern France. But at Tuesday's meeting of ITER's six international partners in Moscow, ministers finally agreed.

\section{It's a deal}

The European Union will now pay half of ITER's US $\$ 5.5$-billion construction costs, much of it coming from France. The other five partners will contribute $10 \%$ each, mostly in the form of equipment and components. Japan will win $20 \%$ of the manufacturing orders despite its $10 \%$ share. The European Union has also agreed to support a Japanese candidate for ITER's director-general, and Japan will provide $20 \%$ of the project's scientists, instead of the $10 \%$ to which it is entitled.

Up to $8 \%$ of the ITER construction budget will go towards partner facilities. These will now be built in Japan, and three likely candidates are a supercomputing centre, an upgrade of the JT-60 and a materials testing facility.

Such centres would carry out research in parallel with ITER, so that if it is successful, work can start straight away on the next step a prototype fusion reactor called DEMO. For example, the testing facility would use accelerators to find building materials that will stand the extreme conditions of a fusion power plant. Some even say that DEMO could be operational by 2030.

The Europeans are, of course, ecstatic.

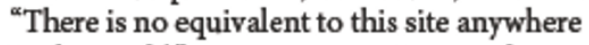
in the world," says Jean Jacquinot, a plasma physicist who played a leading role in the Cadarache bid.

Cadarache is already home to more than 2,000 nuclear engineers and scientists, he points out. Most of them work on fission energy, but Jacquinot says ITER could still use their expertise. The site's use as a nuclear research facility means the project will have the necessary access to large amounts of electricity and water-cooling facilities, Jacquinot adds.

Meanwhile, Japan's researchers are looking for someone to blame. "Japanese scientists

\title{
Clear skies raise global-warming estimates
}

\section{MUNICH}

For more than a century, dust and aerosols in the atmosphere have been blocking some of the Sun's radiation, shielding us from the worst effects of global warming. The question has always been: how much? Now, as cuts in pollution allow the skies to clear, an attempt to quantify the effect on future temperatures has produced an alarming conclusion.

Even under relatively cautious assumptions about past and present aerosol cooling, the study suggests that global warming could easily exceed the upper extreme predicted by the Intergovernmental Panel on Climate Change (IPCC), as dean-air measures take effect.

"Things could get really uncomfortable," says lead author Meinrat Andreae, an atmospheric researcher at the Max Planck Institute of Chemistry in Mainz, Germany. ${ }^{\text {"The climate }}$ system is much more sensitive to human per-

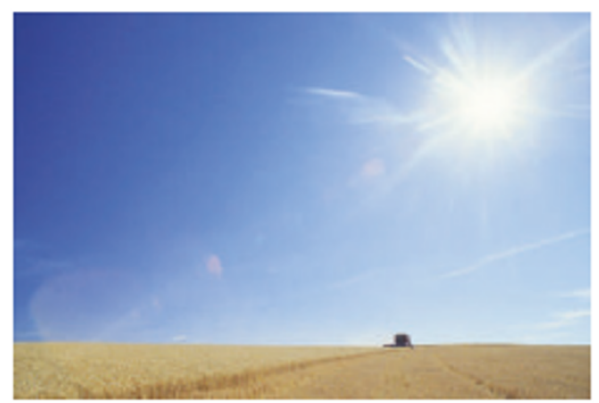

How much has pollution shieldedus from the Sun?

turbations than has been thought. If our model is right, things could become totally uncontrollable in the second half of the century."

That is quite a big 'if', however. As cars, industries and power plants worldwide become cleaner, atmospheric concentrations of emitted aerosols are expected to drop substantially. But how global temperatures will respond depends on how big the masking effect was in the first place - and that is the wild card in the climate game.

The problem is that different methods of estimating the cooling effect arrive at vastly different values. Trying to work it out from our understanding of how aerosol particles behave in the atmosphere suggests that the amount of solar energy reaching the ground will be reduced by anything from 0 to 4.5 watts per square metre. Working it out from a best guess of how sensitive the atmosphere is to greenhouse gases and how much warming we have seen so far gives 2 watts per square metre.

Such uncertainty has deterred researchers from estimating the effect of losing our aerosol shield. But as the skies are already starting to brighten (see Nature 435,$135 ; 2005$ ), the question has become critical. 
